\title{
XX. A new eudiometer, accompanied with experiments elucidating its application
}

\section{William Hasledine Pepys Esq.}

To cite this article: William Hasledine Pepys Esq. (1807) XX. A new eudiometer, accompanied with experiments elucidating its application , Philosophical Magazine Series 1, 29:114, 116-126, DOI: $10.1080 / 14786440708563712$

To link to this article: http://dx.doi.org/10.1080/14786440708563712

曲 Published online: 18 May 2009.

Submit your article to this journal $\sqsubset \pi$

Џ Article views: 3

Q View related articles $\sqsubset$ 
nitude of the projection, but the estimation just mentioned, it follows, by calculation, that the apparent diameter of the planet Vesta is only $0 \cdot 488$ seconds, and consequently only half of what I have found to be the apparent diameter of the fourth satellite of Saturn.

This extraordinary smallness, with such an intense, radiant, and unsteady light of a fixed star, is the more remarkable, as, according to the preliminary calculations of Dr. Gauss, there can be no doubt that this planet is found in the same region between Mars and Jupiter, in which Ceres, Pallas, and Juno, perform their revolutions round the sun; that, in close union with them, it has the same cosmological origin; and that, as a planet of such smallness, and of so very intense light, it is comparatively near to the earth. This remarkable circumstance will no doubt be productive of important cosmological observations, as soon as the elements of the new planet have been sufficiently determined, and its distance from the earth ascertained by cal-. culation.

Lilienthal, May 12, 1807,

XX. A new Eudiometer, accompanied with Experiments elucidating its Application. By Wrluiam Hasledine Pepys, Esq. *

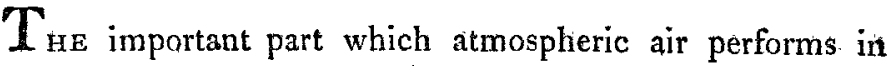
maintaining the principle of life in animals, in combustion of every description, the acidification and oxidation of a great variety of substances, and in numerbus other processes both of nature and art; gives a high degree of interest to every thing calculated to extend our knowledge of its nature and properties.

The evidence furnished by modern chemistry of the existence of many other aẹriform substances increases this inierest, especially when it is considered that, owing to their possessing some of the most obvious properties of atmo-

From Transactions of the Royal Saciety, pazt ii. for 1807.

spheric 
spheric aip, as transparency, elasticity, and a power of great expansion on being exposed to an increase of temperature, they were, with very few exceptions, till lately, confounded either with common air, or not even suspected to exist.

When to these considerations we add the facility with which some products, especially the gaseous, are evolved, in circumstances under which, in the present state of our knowledge, we should hardly look for them ; the power they possess of decomposing each other, and by an interchange and new arrangement of principles, of producing compounds possessing properties alcogether different from those of the ingredients supposed to be present; and the facilities which every new detection of unsuspected principles affords towards the discovery of others, and consequently the composition or analysis of bodies before held to be simple, it will not appear a matter of surprise that the subject of eudiometry should have obtained a considerable degree of attention from modern philosophers.

This would be an.improper place to enumerate all that has been done or proposed by different men of eminence towards the production of something like a perfect system on this important subject; yet some allusion to their labours appears to be indispensable, and will be the means of preventing some circumlocution in our further progress.

Hales* appears to be the first who observed absorption to take place in common air, on mixing it with air obtained from a mixture of $W$ alton pyrites and spirits of nitre; and that in this process from being clear they became "a reddish turbid fume."

Dr. Priestley, as he informs us in his "Observations on different Kinds of Air + ," was much struck with this experiment, but never expected to have the satisfaction of seeing this remarkable appearance, supposing it to be peculiar to the Walton pyrites ; till encouraged by a suggestion of $\mathrm{Mr}$. Cavendish, that probably the red appearance of the mixture depended upon the spirits of nitre only, he tried solutions of the different metals in that acid, and, catching the air

* Statical Essays, vol. i. p. 224 ; vol. ii. p. 280.

+ Phil. Trans. for 1772 , p. 210.

$\mathrm{H} 3$

which 
which was generated, obtained what he wished. To the air thus produced be gave the name of nitrous air, and, from its possessing the properties of absorbing that portion of atmospheric air which he calls dephlogisticated, first proposed its being used as a test for ascertaining the purity of air. His method of proceeding was ingenious and simple; known quantities of the air to be tried, and of nitrous:gas, being mixed, were admitted, after the diminution of volume occasioned by their union, into a graduated tube, which he denominated a eudiometer.

It was with the test of nitrous gas that Mr. Cavendish* made his masterly analysis of the air at Kensington and London; and by many laborious processes and comparative trials, obtained results, the accuracy of which has been more distinctly perceived the more the science of chemistry has advanced.

The slow combustion of phosphorus, which unites with the oxygen to form an acid, and the decomposition of the fluid sulphuret of potash, are certain methods of separating combinations consisting of oxygen and azote; but the decurposition is effected so slowly by the action of these substances, that it became a desirable object to discover some means for accelerating the process. This was supposed to have been effected by Guyton, who proposed heating the sulphuret of potash; in doing this, sulphurated hydrogen gas, however, is frequently evolved, which, mixing with the residual gas, increases its quantity, and renders the result fallacious.

The green sulphate of iron impregnated with nitrous gas, first discovered by Dr. Priestley, and recently used by $\mathrm{Mr}$. Davy for eudiometrical purposes, from its possessing the property of absorbing oxygen gas from the atmosphere, is much to be preferred to the method with nitrous gas, as the green sulphate of iron does not combine with the other gases with which the nitrous gas is commonly found to be contàminated, and more certain results are obtained.

Having had occasion to repeat many of the experiments

* Phil. Trans. for 1783. 
of others, and to make some new ones, I soon found what every one who has been engaged on the same subject must have experienced-that an apparatus more commodious than has yet been proposed, and at the same time capable of giving correct results, with the greatest minuteness, was still a desideratum in eudiometry. To detail the various ideas that presented themselves on the subject, would be an unnecessary encroachment on the time of this society; but as I at last succeeded in contriving an instrument possessing the above properties in a very eminent degree, $I$ flatter myself I shall not be thought intrusive in offering a description of it.

This apparatus, (Plate IV.) which is of easy construction, and extremely portable, consists of a glass measure $\mathrm{M}$, fig. 1, graduated into hundred parts; a small gum-elastic bottle, B, fig. 2 , capable of containing about twice the quantity of the measure, and furnished with a perforated glass stopper, $\mathrm{S}$, which is well secured in the neck of it by means of waxed thread wound tight round it; and a glass tube, T, fig. 3, also graduated, but into tenths of the formed divisions, or into thousand parts of the measure.

The glass stopper,. made fast in the neck of the gumelastic bottle, as above mentioned, has its exterior end ground with emery, exactly to fit the mouth of the measure; to the lower end of the graduated tube $T$, is cemented a small steel cock, which is secured into the neck of a very small gumelastic bottle by means of waxed thread, SB, fig. 4: the other end of the tube is conical, so as to present a very small orifice.

Besides this, the apparatus is furnished with a kind of moveable cistern $\mathrm{C}$, in which the tube can be slid easily up and down, and yet in such a manner that the water or other liquid in the cistern may not pass. This is easily accomplished by means of a cork fitted into its mouth with a perforation through its axis to receive the tube. The cistern, when in use, is to be filled with water or mercury, as the experiment may require, and becomes a secondary cistern for the measure, as will be more elearly understood by the following description of the method of performing experi ments with this instrument. 
Phit.May. Fol. XXIX. Plate IV.

Pepeyes Cindermeter?

Fig. 1 .

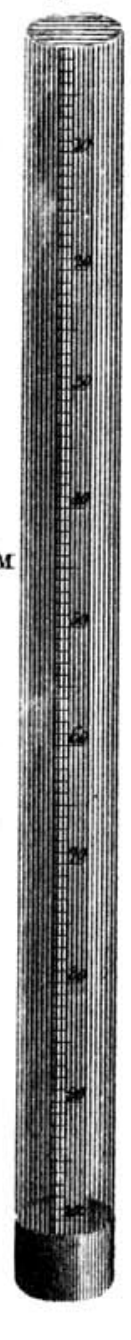

Fig. 3.

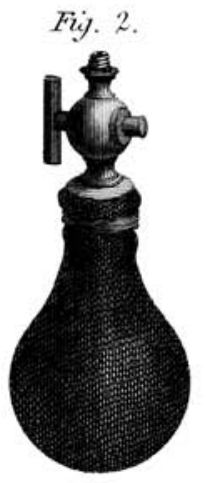

Fig. 4.

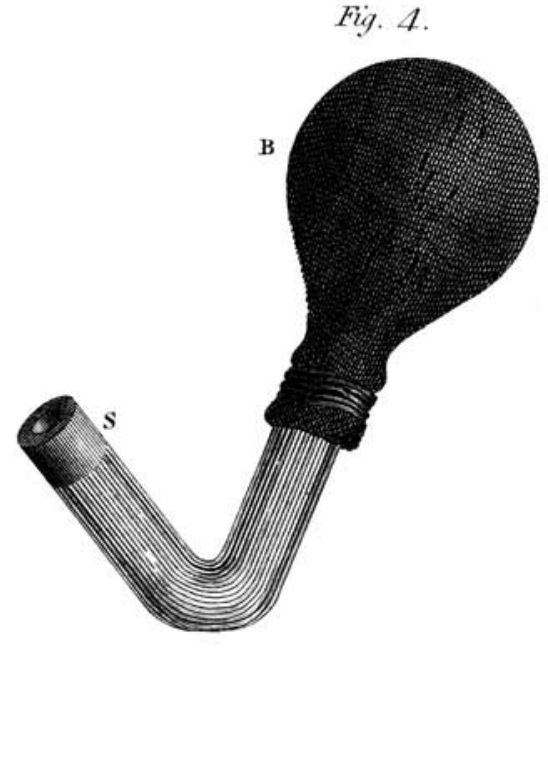

Fig. 5.

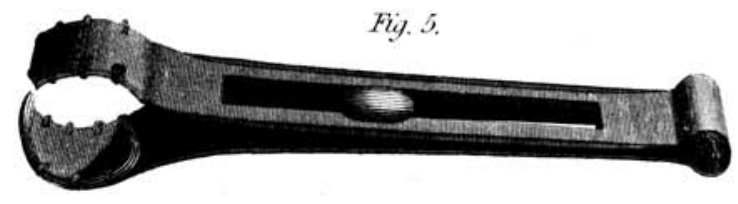


The measure is filled with the air or gas, over mercury, in the usual manner, and the elastic bottle is charged with the solution intended to be employed as the re-agent; the orifice of the stopper is then inserted into the mouth of the measure in the mercury, and pressed home to its place.

The bottle and measure being thus united, are to be firmly held at the joint. Upon pressing the former, a portion of the fluid is injected into the latter, and the gas suffers a degree of compression, by which the action of the affinity between it and the fuid is accelerated. On taking off the pressure, the bottle, by its elasticity, endeavours to obtain its original form, and receives back the fluid. This process should be continued as long as any absorption is observed to take place. When absorption ceases, the bottle is to be separated from the measure under mercury, and the quicksilver which remains in the measure being brought to the level of that in the cistern, the quantity of absorption is then to be determined, which is done as follows :

Suppose atmospheric air has been the subject of the experiment, and consequently a large residuum left; first note the hundred parts, and then to obtain a knowledge of the fractional parts, remove the measure into the small cistern in which the graduated tube filled with mercury is placed: slide the tube above the surface of the fluid in the measure, and, opening the stop-cock, suffer the mercury to descend till it bas drawn the fluid in the measure to a regular division; then stop the cock, and register the hundred parts on the measure, and the thousand parts on the graduated tube; the united quantities give the sum of the residual gas. $\mathrm{Ob}$ serve well in registering the thousand parts, that the fluids are exactly on a level on the outside and inside of the measure; this may be easily effected by pouring out a portion of the liquid of the small cistern, or adding thereto.

If instead of atmospheric air, a gas is tried, which, so far as it is uncontaminated, can be nearly wholly absorbed by the re-agents employed, the process becomes exceedingly simple; for if the residum is under a hundred part of the measure, it may be transferred completely into the graduated tube, and its quantity at once ascertained. 
The stopper $S$ would have injected the fluid with greater velocity had it been straight; but it would not then have been so convenient in the analysis of compound gases, where both mercury and hot solutions are occasionally employed, as the mercury would have so compressed the fluid in the bottle, in introducing it under that metal, as to have thrown out a portion of its contents, and also have robbed the hot solutions of the temperature which was necessary for their perfect action.

As to the size of the measure $M$, I have generally preferred the cubic inch divided into hundred parts. This is easily effected by taking a stout glass tube about half an inch calibre, sealing one end, then weighing 3422 grains of mercury, equal to 252 grains of distilled water, at temperature $50^{\circ}$ Fahrenheit. This is introdnced into the tube; the extra length is cut off with a sharp-edged file, care being taken to leave a sufficient portion to grind the perforated stopper $\mathbf{S}$ into its mouth.

The divisions are obtained by a small measure, made from a glass tube sealed at the end, and cut off exactly to the hundred parts of a cubic inch, equal to 34.2 grains of mercury, which being ground tlat, is stopped by a piece of plate glass, and the divisions marked by the diamond upon the introduction of each hundred part of mercury into the measure $\mathbf{M}$.

The tube $\mathrm{T}$ is divided into tenths of the measure $\mathrm{M}$, or thousand parts of a cubic inch. This is done by measuring one hundred part of a cubic inch into the tube, and dividing it into ten parts, marking the divisions with fluoric acid or black enamel.

To prove the accuracy of the instrument, I shall proceed to relate a few experiments made with it.

The elastic bottle being filled with the solution of sulphate of iron impreganated with nitrous gas, and the measure with atmospheric air, they were united, and by gentle injection $\frac{315}{1000}$ were absorbed.

If the experiment is made hastily, the impregnated solution loses a portion of its nitrous gas, which must be again absorbed by a solution of green sulphate of iron. 
For ascertaining the purity of nitrous gas, the bottle may be charged with the solution of green sulphate or muriate of iron.

For carbonic acid gas, with lime or barytic water.

For oxygen gas, with the solution of green sulphate of iron impregnated with nitrous gas.

For sulphurated hydrogen gas, a solution of nitrate of silver was put in the elastic bottle, and sulphurated hydrogen gas $f$ into the graduated measure. Upon the first injection, the solution took a black flocculent appearance, and a considerable portion of the gas was absorbed. After repeating the process as before mentioned, the residuum was ग.0.

The: instrument may be likewise generally applied to the analysis of mixed gases.

I hove been able completely to separate the carbonic acid gas from the sulphurated hydrogen by a solution of the nitrate of silver or of mercury, employed hot. The carbonic acid gas is expanded in this process, but on standing over mercury it returns to its original volume. The sulphurated hydrogen, in this instance, is taken up by the metallic nitrate. It should be here observed that the acetite of lead must not be used, as the carbonic acid gas, even at a high temperature, decomposes it, forming carbonate of lead.

The propriety of using, the solutions hot, will be seen, when we recollect that the carbonic acid gas is soluble in the water: of solution at the common temperature of all these componnds.

Nitrous gas and carbonic acid gas may be separated by means of the hot solution of the green sulphate of iron. To effect this, heat a solution on a glass capsule, over a spirit lamp, until ebullition. Having filled the measure with the compound gas, charge the elastic bottle with the bot solution, and unite them. The nitrous gas, in two or three injections, will be absorbed, changing the colour of the solu-

* Obtained from oxymuriate of potash by heat.

† Obtained from sulphuret of potash by diluted muriatic acid, and collected and preserved with the grearest care. 
tion, while the carbonic acid gas will be a little rarefied, but no absorption of it will take place.

Previous to these experiments on the compound gases, I had tried several on the carbonic acid, sulphurated hydrogen, and nitrous gases in their unmixed states. 100 parts of pure alcohol at the common temperature will absorb 70 parts in volume of carbonic acid, and the same quantity of sulphurated hydrogen. Alcohol impregnated with the latter, precipitates the solutions of the nitrates of lead, silver, and mercury, of a dark brown colour. Nitric acid of the specific gravity $1 \cdot 4$, and also of $1 \cdot 25$, absorbs carbonic acid gas, without any apparent change in the nitric acid. Sulphurated hydrogen gas is also absorbed by nitric acid, which occasions a slight milky cloud or precipitate therein.

The solutions of nitrates of barytes, strontian, and lime, absorb carbonic acid gas equal to half their volume, without any apparent alteration.

Solutions of nitrates of barytes, strontian, and lime, also absorb sulphurated hydrogen gas, equal to six-tenths of their volume, with a slight change of colour; the solutions thus impregnated precipitate solutions of nitrates of mercury and of silver, and acetite of lead of a dark brown colour, and would be useful as chemical re-agents.

Carbonic acid gas, as I have before stated, decomposes solutions of the acetite of lead, hot or cold, forming a precipitate of carbonate of lead.

Carbonic acid gas is absorbed by the solution of the green sulphate of iron under the temperature of $100^{\circ}$ Fahrenheit; but this is only the action of the water of solution. If the temperature be near boiling, or above $180^{\circ}$ Fahrenheit, the solution increases the volume of the gas without the slightest absorption; after carbonic acid gas has in this way been treated with the hot solutions, it is still soluble in water at the common temperature, or in aqueous solutions of lime or alkali.

Nitrous gas is absorbed by solution of sulphuret of potash, with a separation or formation of sulphur. Upon injecting the solution the sides of the measure take a milky appearance, 
appearance, which on the secopd injection is washed down insoluble in the liquor. About 80 parts from 100 of gas are absorbed.

Nitrous gas is also absorbed by nitrate of copper in sola * tion, without any peeuliar alteration.

In these experiments great care must be taken not to increase the temperature of the gas by the hand. 'To prexent this, I use a pair of : sinall circular-mouthed forceps, lined with cloth, which firmly grasp the measure, fig. 5; and if the experrments should in any way be delayed; a corresponding manometer will always be sufficient to correct the error occasioned by change of atmospheric temperature and pressure.

To ascertain the quantity of carbonic acid gas contained in oxygen gas (of a known purity) after combustion or decomposition of carbonaceous substances, lime water will be found sufficient.

If it is required to know the purity of the oxygen gas after the carbonic acid gas has been absorbed, the best method and the least liable to error, is to withdraw the residual oxygen gas by means : of the small graduated tube before described.

To do this, remove the measure into the small cistern of mercury; press the quicksilver ont of the small bottle by the fingers and thumb, and let the tube rise a sufficient height within the measure, that the bottle, extending itself, shall withdraw the whole of the gas from the measure, taking care that the oock be stopped as soon as it has completed it, and also to prevent the solution from entering the tube

If the epening of the tube is small, it may then be drawn down inte the nercury, without the possibility of any portion of the gas escaping, while the measure is dried or cleaned, or a fresh : ane flled with mercury supplied to receive it.

This way of transferring will be found very advantageous, particularly in the separation of gases, liable to be absorbed under certain temperatures, and also where a new series of 
re-agents are to be employed, as from the depositions of former solutions on the glass measure a source of considerable error would arise.

The residual oxygen gas being thus transferred into a clean dry measure, the processes before described for examining oxygen gas may be then used; or the quantity of carbonic acid gas (for examination) being found by lime water, another measure of the gas may be tried, first with the green sulphate of iton impregnated with nitrous gas, and then with the green sulphate in solution only : these will take up both the carbonic acid gas and the oxygen gas, leaving only such residual gas as the oxygen might have originally contained.

Transferring is not here necessary, as the two solutions may be used one after the other, taking care to use the solution of green sulphate last.

Where it is not requisite to transfer the gas into a dried or clean measure previous to the use of another solution, as in the instance I have just mentioned, a quantity of the first solution may be withdrawn, by simply filling the elastic bottle with mercury, then joining it to the measure, and by inclining the measure, the mercury by its gravity will displace the former solution.

If at any time the gas should get drawn into the elastic bottle, it may be very easily returned into the measure, by inclining sometimes the bottle, and sometimes the measure. The only error that could arise from this is, an increase of temperature in the gas, which may be rectified by plunging the whole apparatus into mercury or water of the standard temperature.

The advantages of this construction of the eudiometer will be readily perceived by all those who are in the habit of making ehemical experiments. The portion of gas to be examined is completely under command; it may be-agitated without the least fear of the intrusion of any atmospheric air, and the process thereby very materially shortened. The gum-elastic is a substance so little acted upon by chemical agents, that a great variety may be employed; and, above all, we can very conveniently use hot solutions, which will 
be found an important auxiliary in the examination of some compound gases.

Simple as this instrument may appear, it is calculated to extend our knowledge of the different kinds of air, by the precision and accuracy which it enables us to obtain, and which solely constitutes the value of every experiment. A degree of confidence is inspired from knowing that we can depend upon our results; and hence much valuable time, which would have been wasted in uncertain, if not useless, investigations, may be directly: applied to the advancement of science.

\section{On Public Libraries.}

\section{To $M r$. Tilloch.}

As you have, in some former Magazines, paid an atténtion to the establishment of public subscription libraries; that is, such libraries as are supported by, the subscription of its nembers, the property whereof remains with them, in contradistinction to the common circulating libraries, I beg leave to forward you a small communication on that subject. I shall give you a plain relation of facts, which took place about four years ago, at North. Shields, in the county of Northumberland, by which the laudable object in view was completely attained. And I shall subjoin a plan pursued by the nembers of the same library, by which they have now built a very excellent house, and are not only rent free, with most comfortable accommodations, but I believe their receipts, in part, pay also tbeir worthy librarian. About the time mentioned above, three or four gentlemen living in North Shields, and who subscribed to an extensive library of that kind about seven miles off them, met, and were conversing about the expense of threepence per volume to them for carriage in addition to their annual subscription of $21 \mathrm{~s}$. One of the gentlemen proposed to print off as many hand-bills as would circulate very freely through the town, recommending to the inhabitants the establishment of a public library, and at the same time proposing a meeting of 